\title{
O ESPAÇO GLOBAL DE QUE FAZEMOS PARTE
}

\author{
Teresa LAgo ${ }^{1}$
}

Aqui, será o "espaço" físico, o objecto. Para ir direita ao assunto, proponho: numa noite límpida e sem luar deite-se na relva, num local não poluído pela iluminação; olhe bem para o "céu" profundo, esmagador, nos milhares de objectos cintilantes. Contemple a sua beleza. E lembre-se que ocupa uma "nave" que se desloca, nesse espaço, a cerca de $29,8 \mathrm{~km} / \mathrm{s}$, em torno de uma estrela (como tantas outras...), o Sol. Mas tenha em conta que, em simultâneo, também ele (e todo o sistema solar) rodam a cerca de $220 \mathrm{~km} / \mathrm{s}$ em torno do centro da Via Láctea, que pode vislumbrar sobre si, deslumbrante (fig. 1).

Ainda mais, a Galáxia, por sua vez, e também as diversas galáxias da vizinhança, "aceleram" a 1000 km/s, em direcção ao "Grande Attractor" localizado a 150000000 anos-luz (Para completar a imagem, recorde que esta unidade, o ano-luz, que usamos em astronomia para referir as distâncias, é da ordem de $10000000000000 \mathrm{~km}$ - a distância que a luz percorre num ano à velocidade de $300000 \mathrm{~km} / \mathrm{s}$ ).

Sem esquecer esses factos contemple a imensidade que o cobre e deixe-se "mergulhar" por algum tempo no abismo que é o espaço. Sinta a vertigem desse mergulho, que não deixa de ser perturbador. E tenha presente que afinal é também parte dele, em continuidade.

Falemos então do espaço. Olhemos "para fora da Terra" adoptando a visão da astronomia: espaço é tudo o que nos rodeia, exterior à Terra, objectos incluídos. Quer façam parte do sistema solar - planetas e seus satélites, asteróides, cometas, fragmentos ou poeiras do espaço interplanetário - quer sejam material galáctico: as estrelas - ou o que resta delas na sequência de ventos e ejecção mais ou menos violenta do material que as constitui, ou mesmo os seus despojos mortais - ou as nuvens moleculares, expectantes ou já em vigorosa contracção para formação de nova geração de estrelas, ou as poeiras do espaço interestelar. Ou mesmo material extra-galáctico. De fora, fica a Terra, mesmo sabendo que o seu estatuto não é diferente - ou será?

Recebido: Março 2015. Aceite: Junho 2015.

1 Teresa Lago é Professora catedrática e investigadora (reformada) da Universidade do Porto. Criou na UP a primeira licenciatura do país em astronomia (1984), um mestrado europeu (1994) e o programa doutoral (2003). Fundou o Centro de Astrofísica da UP (1988) que dirigiu durante 18 anos. Foi Presidente da Sociedade "Porto 2001 - Capital Europeia da Cultura" (1999-2002). Foi uma das 22 personalidades europeias escolhidas para o conselho científico fundador do Conselho Europeu de Investigação (European Research Council, (2005-2013). Recebeu o prémio "Henri Chrétien" da American Astronomical Society (1985). É membro da Academia Europeia (1992) e foi eleita Secretária Geral Adjunta da União Astronómica Internacional (2015-2018). Email: mtlago@astro.up.pt 


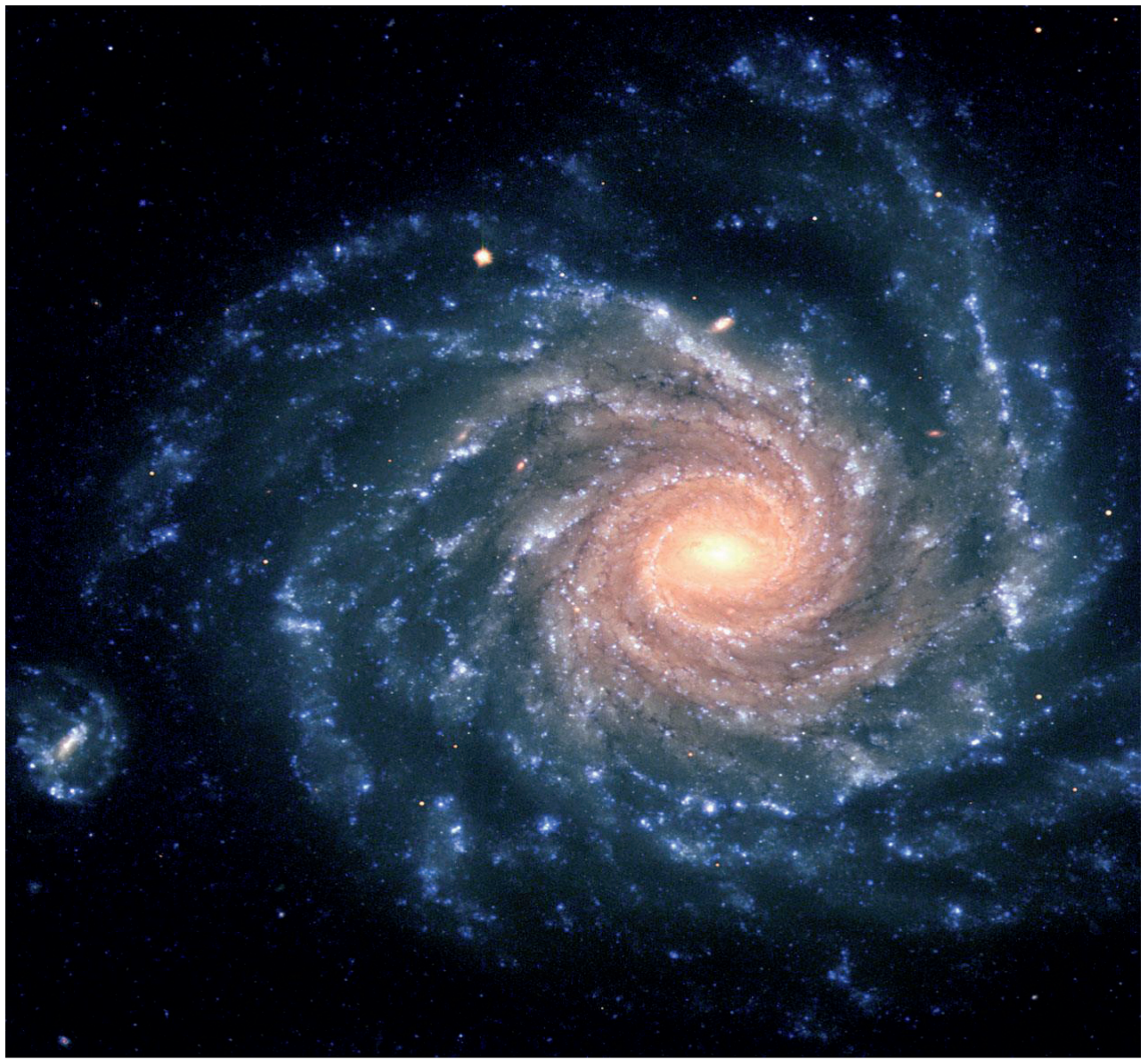

Fonte/source: ESO

Fig. 1 - Se pudéssemos ver de topo a Via Láctea... A galáxia NGC 1232 é muito semelhante à Via Láctea, mas com o dobro do diâmetro - 200000 anos-luz. Está à distância de 61000000 anos-luz e, apesar disso, nesta imagem obtida com o telescópio VLT identificam-se claramente numerosos detalhes: 0 núcleo central da galáxia e a estrutura dos braços espirais, povoados de jovens estrelas muito brilhantes (e azuladas), de zonas de formação estelar e de nebulosas que reflectem a luz dessas estrelas ainda nelas embebidas. Se esta fosse a Via Láctea, o Sol estaria num dos braços espirais, distando do centro pouco mais do que um quarto do raio. Não sendo o Sol particularmente brilhante, não seria identificável nesta imagem.

Que dizer da Terra... com um raio cerca de 100 vezes menor que o Sol?

Fig. 1 (source ESO) - If we could see the Milky Way top down... The NGC 1232 galaxy is very similar to the Milky Way but twice in diameter - 200,000 light years across. It is at a distance of 61 million light years and yet in this image taken with the VLT telescope we can identify a large number of structural details: the nucleus of the galaxy, the spiral arms populated with very bright young bluish stars, star forming regions and nebulae that reflect the light from the stars still embedded in them. If this were the Milky Way, the Sun would be located in one of the spiral arms at a distance from the centre around one quarter of the radius. Not being particularly bright the Sun would not be identifiable in this picture. What about the Earth... with a radius approximately 100 times smaller than the Sun's? 
Torna-se sempre mais simples avançar prudentemente, olhando primeiro o sistema solar, e depois daí para fora, porque as escalas de distância, de massa e até de tempo, são mais à nossa dimensão.

Neste contexto, tem sentido adoptar como referência a unidade astronómica - a distância média da Terra ao Sol, cerca de 150000000 km (8,3 minutos-luz). Os sete outros planetas "acreditados", para além da Terra, com órbitas bem definidas em torno do Sol, localizam-se entre 0,4 e 30 unidades astronómicas. Esse espaço é também partilhado por centenas de luas e milhares de asteróides. Um deles, de seu nome "Portugal" (ou asteróide 3933), foi descoberto em 1986 pelo astrónomo dinamarquês Richard West, que lhe deu essa designação em homenagem à associação de Portugal ao ESO (Organização Europeia de Astronomia). Pois bem, Portugal, o asteróide, tem cerca de $10 \mathrm{~km}$ de diâmetro e orbita o Sol a 487 milhões de $\mathrm{km}$ (entre Marte e Júpiter) com um período de 5,9 anos. Mais longe, e até às 35 unidades astronómicas do Sol localiza-se o "cinturão de Kuiper" dominado por objectos gelados, de material volátil (dominantemente gelos de água e de amónia) de pequena dimensão, que poderão a qualquer momento ser atirados para o interior do sistema solar; Plutão, o despromovido planeta do sistema solar (2006), está aí integrado. Ainda mais externa, a "Nuvem de Oort", estende-se das 2000 até cerca de 50000 unidades astronómicas. Será o remanescente do disco proto-planetário original, resultante da nuvem molecular de que se formou o próprio Sol; é "depósito" de um número elevadíssimo de objectos, que passam a ser designados por cometas quando ejectados para o interior do sistema solar. Atingiram-se assim os limites do sistema solar.

Aventuremo-nos para além desses limites! Neste percurso através do espaço é importante não esquecermos que, contrariamente à física e à química em que se podem preparar e controlar as experiências laboratoriais, alterar as condições de experimentação e investigar as inter-relações entre os diversos parâmetros, na astronomia o conhecimento é adquirido apenas através da observação da radiação recebida dos vários objectos. Em astronomia a experimentação é (quase) impossível:

as enormes distâncias a que se encontram os objectos de estudo na prática tornam-nos inacessíveis; com excepção dos planetas do sistema solar mais próximos da Terra ou, mais recentemente, de asteróides ou cometas que dela se aproximam suficientemente; e mesmo assim o acesso é muito complexo e restrito; as condições físicas dos objectos do espaço que estudamos são extremas; por exemplo, as temperaturas e densidades excessivamente baixas do meio interestelar, ou as temperaturas altíssimas das estrelas; ou as elevadíssimas energias envolvidas. A título de exemplo, a densidade do material interestelar (dominantemente um gás muito rarefeito de hidrogénio e hélio, com uma pequena percentagem de poeiras) pode variar entre 0,000 1 e 1000000 átomos por $\mathrm{cm}^{3}$; um "vazio" muito mais perfeito do que o melhor que se consegue produzir em laboratório; para ser mais fácil a comparação - o ar que respiramos tem uma densidade da ordem de 10000000000000000000 moléculas por $\mathrm{cm}^{3}$.

Tudo isto inviabiliza a duplicação dessas condições em laboratório, para fins experimentais. Há casos muito pontuais e emblemáticos de experimentação laboratorial, por exemplo em ligação com a capa dos grãos das poeiras interestelares, tema de algumas 
experiências laboratoriais para melhor tentar entender a sua composição química e como se formam; ou a análise experimental dos meteoritos recolhidos à superfície da Terra, ou as amostras colhidas por sondas espaciais em alguns (muito poucos) corpos do sistema solar. Quase nada, tendo em conta a diversidade de objectos que constituem o espaço!

Em conclusão, o estudo do espaço é feito através da observação, do registo e análise da radiação electromagnética emitida pelos diversos objectos que chega até nós. O que registamos são os fotões de diferentes energias recebidos desses objectos e também a informação sobre as características do meio que atravessam nesse vasto percurso.

Há outros canais de informação que gostaríamos de poder utilizar, se soubéssemos como: raios cósmicos, neutrinos, ondas gravitacionais. Os raios cósmicos (descobertos por Victor Hess em 1912 e que lhe valeram um Prémio Nobel em 1936) são partículas com elevada energia, maioritariamente protões ou núcleos de átomos de hélio; alguns têm origem no Sol, mas também podem ser emitidos por outros objectos da nossa galáxia, ou mesmo de outras fontes extragalácticas e muito distantes. Os neutrinos, partículas com elevada energia, sem carga eléctrica e sem massa (ou com massa diminuta só recentemente calculada), são produzidos na zona mais central das estrelas (o núcleo) pelas reacções termonucleares que dão origem à própria energia das estrelas; outros, de maior energia, estão associados à explosão das estrelas como supernova; a deteç̧ão de neutrinos é talvez a que está mais avançada em termos de desenvolvimento experimental e condições de medida. De referir duas das várias experiências nesta área: Homestake - instalada por Raymond Davies (década de 70) - um tanque com cerca de 380000 litros de perocloroetileno (o produto utilizado na vulgar limpeza a seco) a $1470 \mathrm{~m}$ de profundidade, numa mina de ouro abandonada, no Dakota Sul - resultou na primeira detecção e contagem de neutrinos emitidos pelo Sol; valeu-lhe o prémio Nobel, em 2002, partilhado com Masatoshi Koshiba, também pioneiro na detecção de neutrinos cósmicos com uma outra experiência (Kamiokonde) no Japão, iniciada na década de 80. Este foi um dos observatórios que, em 1987, registou a emissão de neutrinos da explosão supernova S1987A. Ondas gravitacionais identificadas como flutuações na curvatura do espaço-tempo, em resultado do movimento de um objecto massivo e que se propagam pelo espaço (tal como acontece com as ondas detectadas à superfície da Terra na sequência de um evento sísmico); porém, a detecção experimental de ondas gravitacionais não foi ainda confirmada.

Comum a estes três canais é não sabermos ainda como aceder a essa informação em condições estáveis de deteç̧ão e de medida. São canais diferentes e com informação complementar. A sua utilização regular como instrumento observacional está dependente não só do desenvolvimento tecnológico, mas também do avanço do conhecimento.

Resta-nos assim estudar o espaço através da radiação electromagnética.

Para observar e medir a radiação emitida por objectos muito distantes precisamos de recorrer a telescópios de grande dimensão e complexidade que a colectem. É essencial não perder fotões da radiação que nos chega, ténue e preciosa em termos de informação. Torna-se por isso imperioso que esses telescópios, e os instrumentos que os equipam, sejam tremendamente eficientes. Que tenham a mais alta resolução para permitirem investigar os detalhes. Que operem a alta velocidade para permitirem o registo de variações temporais muito rápidas. Que nos permitam observar cada vez mais longe. 
Em princípio, o ideal seria observar a partir do espaço exterior porque a atmosfera da Terra constitui um enorme obstáculo à observação astronómica: absorve e distorce a radiação que a atravessa e é mesmo opaca à grande maioria dela, deixando-se atravessar (parcialmente) apenas por uma gama muito restrita de comprimentos de onda: o chamado "visível" (tipicamente dos 4000 aos 7500 Å), o infravermelho próximo (8 aos 14 micron) e a banda rádio (entre $1 \mathrm{~cm}$ e $11 \mathrm{~m}$ ).

É curioso que a atmosfera terrestre, essencial ao desenvolvimento e manutenção de vida na Terra, seja, em simultâneo, um obstáculo ao contacto dessa vida com o espaço.

A solução seria observar acima da atmosfera. Mas, colocar em órbita um telescópio e instrumentação acessória é extremamente dispendioso! Para se ter uma ideia dos montantes envolvidos, o custo da colocação de material em órbita baixa, isto é, até $2000 \mathrm{~km}$, excede os $20000 €$ por kg de carga; por exemplo, o custo de cada lançamento do space shuttle americano excedeu os $1000000000 €$, sem incluir o custo do desenvolvimento do projecto (cerca de 200 vezes esse valor!). Quando se passa ao espaço exterior à atmosfera o custo das missões cresce ainda muito mais. Não só em termos do transporte, mas também do próprio design e concepção do equipamento, uma vez que a sua manutenção em órbita é de momento impossível. Por exemplo, a missão Rosetta (Agência Espacial Europeia) que com enorme sucesso se "encontrou" recentemente com o cometa 67P/Churymov-Gerasimenko, custou cerca de $1400000000 €$. Afinal, feitas as contas, e atendendo a que a missão decorreu entre 1996 e 2015, isso não corresponde a mais do que 3,5 $€$ por cada europeu ... um custo pequeno para tamanha aventura!

Por isso o "velhinho" Hubble Space Telescope, que tem apenas 2,4 m de diâmetro um telescópio muito modesto mesmo pelos padrões à época da sua colocação em órbita (1990) - foi colocado numa órbita muito baixa: cerca de $550 \mathrm{~km}$ acima da superfície da Terra, para poder ser acedido pelo space shuttle em missões de manutenção. Mas há (e tem havido) diversos telescópios, e mesmo observatórios espaciais, a funcionar em órbitas bem mais altas, completamente fora da atmosfera terrestre. Só assim se poderão registar radiações ultravioletas, raios $\mathrm{X}$ ou raios gama, que a menor altitude serão completamente bloqueados pela atmosfera terrestre. Porém, continuam a ser de dimensão relativamente reduzida. Alternativamente podem construir-se à superfície da Terra telescópios de grande dimensão com custos bem mais modestos. Os maiores, já em operação, podem exceder os $10 \mathrm{~m}$ em diâmetro do espelho colector (por exemplo, o Gran Telescope Canárias com 10,4 m instalado no Observatório de Roque de los Muchachos, nas Canárias). Há ainda a alternativa de construir sistemas inovadores com vários telescópios, que podem funcionar individualmente, ou combinando a radiação recebida por cada um deles em modo interferométrico; um exemplo é o VLT (Very Large Telescope), constituído por quatro telescópios de 8,2 m cada um, e que, quando operado em modo interferométrico se torna equivalente a um telescópio único com $130 \mathrm{~m}$ de diâmetro. A construção do VLT custou cerca de $330000000 €$, um custo modesto quando comparado com o de uma qualquer missão espacial, ou mesmo com o do Hubble Space Telescope (mais de 5 vezes mais dispendioso). O VLT, que entrou em pleno funcionamento em 2001, é propriedade da ESO de que Portugal é membro; está instalado no Observatório do Paranal, um dos observatórios do ESO no deserto do Atacama, no norte do Chile. 
O VLT está equipado com uma nova e extremamente avançada tecnologia - óptica adaptativa - que permite compensar parcialmente o efeito da atmosfera terrestre (fig. 2).

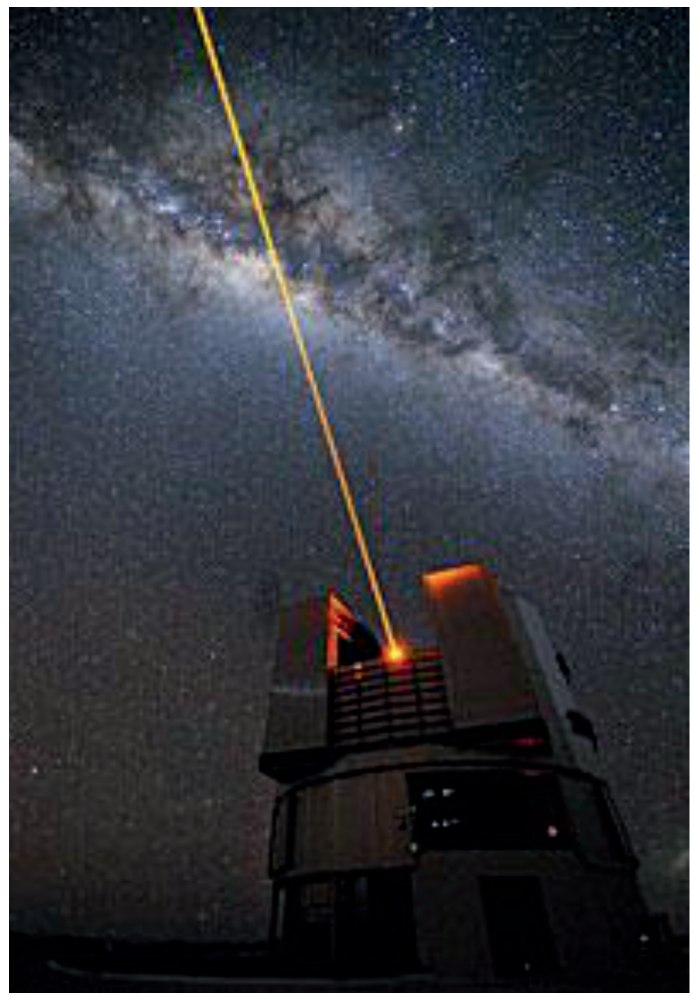

Fonte/source: ESO

Fig. 2 - Uma "estrela artificial" criada para poder compensar o efeito da atmosfera terrestre. A partir de um instrumento acoplado a um dos telescópios do VLT é emitido um potente feixe laser, na direcção da observação; da interacção da radiação laser com os átomos de sódio da alta atmosfera (cerca de $90 \mathrm{~km}$ de altitude), ou com as moléculas das camadas mais baixas (10 a $20 \mathrm{~km}$ ) resulta uma "estrela artificial"; a radiação dessa "estrela" é então utilizada pelo telescópio para analisar e compensar, em tempo real, as distorções produzidas pela atmosfera na radiação recebida do espaço nessa direcção. Fig. 2 - An "artificial star" created to offset the effect of the Earth's atmosphere. A powerful laser beam is emitted in the direction of observation by a laser device coupled to one of the VLT telescopes; the interaction of the laser radiation with the sodium atoms in the upper atmosphere (about $90 \mathrm{~km}$ altitude) or with the molecules of the lower layers (at 10 to $20 \mathrm{~km}$ ) results an "artificial star"; the radiation of such "star" is then used by the telescope to analyse and compensate in real time the distortion introduced by the atmosphere in the incoming radiation from space in that direction.

Um interferómetro ainda mais ambicioso, quer pela tecnologia e operação, quer pelo custo de construção é o ALMA - Atacama Large Millimeter/submillimeter Array (cerca de $1300000000 €$ ); é uma parceria do ESO, América do Norte (Estados Unidos e Canadá) e Japão. Está instalado no planalto de Chajnantor, no deserto do Atacama, Chile, a $5050 \mathrm{~m}$ de 
altitude, e está em funcionamento desde Março de 2013. O ALMA é constituído por 66 antenas de $12 \mathrm{~m}$ e $7 \mathrm{~m}$, que podem ser deslocadas para diferentes configurações, com distância entre antenas variando entre $150 \mathrm{~m}$ e $16 \mathrm{~km}$, dotando assim o ALMA de uma enorme capacidade de zoom e permitindo simular uma antena única com $14 \mathrm{~km}$ de diâmetro... É certo que o ALMA está ainda sob a atmosfera terrestre, mas ela é, a essa elevada altitude, muito mais rarefeita, e quase sem vapor de água porque Chajnantor é um dos locais mais secos à superfície da Terra. É por isso ideal para a observação da radiação milimétrica e sub-milimétrica. Estes comprimentos de onda são característicos da radiação proveniente do interior das nuvens moleculares - os "casulos" onde se estão a formar estrelas - e também dos objectos mais distantes do Universo. A ambição do ALMA é o conhecimento das origens!

Os dados das observações são registados, arquivados, analisados e interpretados para permitirem construir modelos físico-matemáticos dos objectos observados e dos fenómenos que neles têm lugar. Assim se vai construindo o conhecimento em astronomia.

Naturalmente que em qualquer área do conhecimento se fazem estudos teóricos ou numéricos (computacionais) e se recorre a modelos físico-matemáticos; mas esses modelos terão sempre que ser validados. Pela experimentação, se ela for possível, ou, num procedimento mais complexo, pela observação, através da previsão de (novas) propriedades observáveis, que irão permitir testar a consistência do modelo, como é o caso da astronomia. Como um puzzle que se vai resolvendo e em que todas as peças têm que encaixar.

E assim, o estudo do espaço exterior é feito passo a passo, à medida que a observação mais rigorosa, mais completa e de objectos cada vez mais distantes se vai tornando possível. À medida que instrumentos mais eficientes e potentes vão surgindo. Quer se trate de telescópios (para colectar o máximo de fotões), de instrumentos acessórios (para detectar e analisar em mais detalhe essa mesma radiação) ou de computadores (para recolher quantidades crescentes de dados, trabalhá-los e arquivá-los em imensos bancos de dados, e também para construir modelos cada vez mais realistas dos objectos, que são observados).

É assim que chegamos a compreender como é constituída uma estrela, uma galáxia ou mesmo um enxame de galáxias. Como se formam, como evoluem e como terminam. Medimos as suas dimensões e determinamos a distância a que se encontram de nós. Identificamos a sua composição química. Determinamos a sua temperatura, densidade, estrutura e dinâmica. Esse tipo de estudo faz-se não só para os objectos individuais, mas também para o todo: como ocorrem as interacções entre objectos no espaço, como se caracterizam as estruturas de larga escala, como teve origem o próprio universo.

A partir desta Terra diminuta, ousamos questionar-nos sobre o todo, bem para além dos nossos horizontes. Mesmo que a nossa escala de tempos - as poucas dezenas de anos de uma vida - se não possam, de novo, comparar com as escalas de tempo características dos objectos do espaço: uma estrela como o Sol dura cerca de 10 mil milhões de anos; a idade do universo (marcada pelo momento em que a primeira radiação conseguiu escapar e portanto a observação se tornou possível) é da ordem de 13,8 mil milhões de anos. As diferenças brutais de escala, de todas as escalas envolvidas, não nos perturbam. Pelo contrário, agudizam a nossa curiosidade e aumentam a vontade de compreender. E é reconfortante concluirmos dessa investigação que a matéria de que são formados os objectos que estudamos não é diferente da nossa própria - os mesmos elementos químicos, afinal a continuidade do espaço. Apenas as 
condições são muito diferentes. Condições hostis e impossíveis para nós. Apesar do deslumbramento produzido pelas imagens fabulosas que as observações nos revelam (fig. 3).

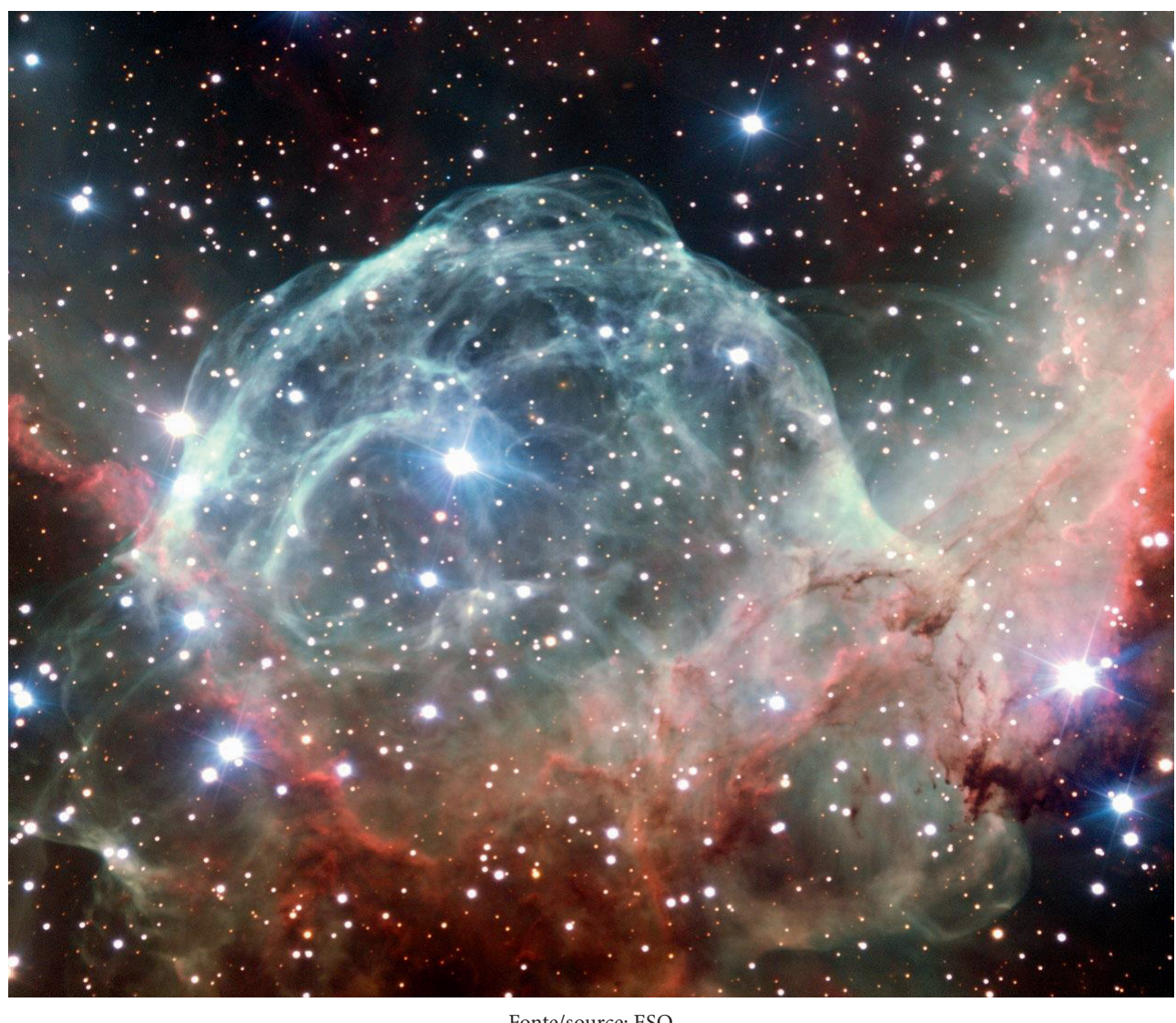

Fonte/source: ESO

Fig. 3 - Bolhas gigantes, não muito longe, no espaço... A imagem da "Nebulosa Capacete de Thor" foi obtida pelo VLT (5 de Outubro de 2012, aquando da celebração dos 50 anos do ESO). A nebulosa, com cerca de 30 anos-luz de dimensão está à distância de 15000 anos-luz. A "bolha" cósmica resulta do impacto do vento da estrela central, muito quente (30 000 a 200000 graus Kelvin) com a nuvem molecular envolvente. A estrela, de massa elevada (mais de 20 vezes a massa do Sol), está numa fase de evolução que antecede a explosão supernova, perdendo material, vigorosamente, através de um vento com velocidade da ordem de $2000 \mathrm{~km} / \mathrm{s}$. Fig. 3 - Giant bubbles in space, not too far away... This image of the "Thor's Helmet Nebulae" was obtained by the VLT at the time of the ESO 50th anniversary, 5 October 2012. The nebulae, about 30 light years across, is at 15,000 light years from us. The cosmic "bubble" results from the impact of the wind blowing from the very hot central star (30,000 to 200,000 degrees Kelvin) with the surrounding molecular cloud. The massive star (more than 20 solar masses) is at the evolutionary stage preceding the supernova explosion, loosing material, vigorously, through the wind which speeds up to $2,000 \mathrm{~km} / \mathrm{s}$.

De facto, sabe bem a relva macia, a partir da qual fizemos o nosso "mergulho", no espaço! 